\title{
Teaching Geometry at University Dialectics of Classics and Modernity
}

DOI: $10.47050 / 66515314.242-257$

Aliya Bukusheva

Technological developments over the past decade have led not only to the formation of "new mathematics", but also to new challenges in the use of technology in the teaching and learning of geometry. The development of big data analysis tools and artificial intelligence methods has revived interest in modeling methods. Therefore, the interdisciplinary approach, which includes geometric education, has become of great interest to prospective mathematics teachers. The interdisciplinary connections between geometry and other subjects are not always properly reflected in teaching geometry at university. Unfortunately, nowadays, the distance between abstract geometry and its application area is noticeably increasing. A student sees the geometrical objects he studies as independent entities that have nothing to do with objective reality. Achieving interdisciplinarity at school means redefining what teacher mathematics education can be. At the higher education level, the interdisciplinary approach manifests itself most profoundly in students' research work. In the present chapter, some aspects of teaching geometry to students (prospective mathematics teachers) based on the interdisciplinary approach are considered.

\section{Keywords:}

teaching geometry

teacher education

teacher preparation 


\section{Introduction}

The process of teaching geometry at pedagogical as well as classical universities has deep roots and strong enduring traditions that have developed and changed according to the needs and demands of society, based on mathematical, psychological, and pedagogical scientific research.

Modern geometry is divided, both by the main objects of study and by the methods used, into many disciplines that have both fundamental and applied value. All share a unified geometrical approach, which consists in the fact that attention is primarily paid to the qualitative characteristics of these objects, and also in the quest for clarity at all stages of research, from the problem's definition to the formulation of the result. Geometry has numerous applications, which in turn stimulate its development.

Currently, there are two main sources of geometry's development. First, in the last thirty years, geometry has changed its content, turning from classical geometry to interdisciplinary geometry, acquiring a qualitatively new face. The geometric view of the world permeates all modern mathematics; in most of its sections, geometric language is used, geometric methods are applied, and mathematical objects are geometrised. Often, the penetration of geometric ideas leads to the creation of new theories, setting new problems.

Second, geometry has become the main language of the natural sciences, especially physics. Also, the application of software packages allows the building of mathematical and computer models, as a result of which we can master fundamental knowledge and learn its practical application.

Based on an analysis of the research literature published since 2008, the survey of ICME-13 emphasises seven major research threads. These are the use of theories in geometry education research, the nature of visuospatial reasoning, the role of diagrams and gestures, the role of digital technologies, the teaching and learning of definitions, the teaching and learning of the proving process, and moves beyond traditional Euclidean approaches (Sinclair et al., 2017).

Technology in geometry education has become relatively mainstream, yet there is still not enough research into its specific effects. Technology continues to evolve and rapidly change both the everyday world and the classroom. Students and teachers are 
increasingly using digital tools throughout the day. It is thus becoming more and more necessary to better understand how new and emerging digital tools can be used effectively.

The usage of some technologies, such as dynamic geometry environments systems, enriches the content of mathematics education and introduces new opportunities in the learning process. This increases the relevance of methodological problems of the determination of the content, location, and nature of the mathematical software packages used in the structure of mathematics education.

The purpose of the present study is to examine the interplay between teaching geometry and interdisciplinary mathematics to students (prospective mathematics teachers). In the following sections, we present the relevance of geometric education, experimental mathematics, and the complementarity principle that combines these two trends in the education of mathematics teachers. The complementarity principle ensures that the training of the future mathematics teacher is interdisciplinary. The methodology of the research consists of the analysis and generalisation of the scientific research results of Russian and foreign scientists specialised in the sphere of teaching geometry in the framework of higher education and is based on productive and research approaches.

\section{Theoretical framework}

Nowadays, the following two trends in the process of teaching geometry at university can be distinguished.

The first one is connected with the situation wherein modern geometry, as well as other fields of mathematics, applies digital technology to solve its problems. Thus, computer geometric modeling has developed considerably during the last decades. Computer methods of problem solving actively penetrate numerous applications of modern geometry: engineering, design, pattern recognition, etc. Many new programmes have been developed which allow the visualisation of geometric objects, the demonstration of their features, and set up computer experiments to test hypotheses. According to this trend, "experimental mathematics", with its own principles, methods, and criteria, is becoming more developed and acceptable.

Many scientists have paid attention to the unity of the experimental and theoretical principles of mathematics as well as to the significance 
of these principles for both mathematical science and education. Thus, much prominence to mathematics' experimental methods is given in V.I. Arnold's works. One cannot help but refer to Arnold's statement in this regard: "Mathematics is an experimental science. It is definitely a part of theoretical Physics and Science. [...] The ability to build up adequate mathematical models should be a significant and integral part of Mathematics education. Success depends not only on the application of ready-made decisions but mainly on the Mathematical approach to the real-world phenomena" (Arnold, 1997). Undoubtedly, the experiment is the main source of scientific cognition. An experimental approach in mathematics has been developed and spread out due to computers.

The computer model serves as a means of the relation and essence of geometric objects. Accordingly, models of geometric objects are essential tools for research, carrying out experiments, proving hypotheses, and clarifying facts in the process of problem solving. These models allow us to distinguish consistent patterns and formulate generalised issues.

From a psychological point of view, Vygotsky showed the role of tools in the development of a child: external objects (tools) are the main way to assist a person with their intellectual operations (Vygotsky, 1994 [1934]). Vygotsky and Leontyev studied a mechanism of internalisation, whereby if a student does not have some intellectual operation, it is necessary to "carry it outwards". After performing actions with this external reflection "by hand", external operations will be automatically transferred to internal ones, and after internalisation, a new psychological tool will be formed (Leontiev, 2009 [1977]).

From a mathematical point of view, Poincaré noted that mathematics is based on operating with external tools: "What is geometry for a philosopher? This is the study of a certain group. Which one? Groups of rigid body motions. How do you define this group without forcing some rigid bodies?" (Poincaré, 1921). Following Vygotsky's idea about replacing the tools of the external world with signs, you can look at the language means of mathematics from this point of view. The emergence of a geometric view of algebraic concepts, therefore, is a way to translate the mechanisms of visual thinking into an internal plan of new algebraic ideas.

Among all the approaches to technological support in learning mathematics, dynamic geometry is the most successful. This fact 
is confirmed by a large number of implementations of this idea and the large number of teachers and students taking advantage of its possibilities. Using dynamic geometry, teachers and authors of educational materials solve various problems, from quick drawings of attractive figures to the preparation of tasks for mathematical Olympiads (Chartouny et al., 2019; Papert, 1980; Pozdniakov, 2019; Thomas \& Palmer, 2014).

Teaching modern systems of computer mathematics provides students with the following opportunities. Firstly, it helps to form skills in setting and solving computer tasks. Secondly, knowledge of modern systems of computer mathematics allows the use of computers as the main cognition tool. Thirdly, the organisation of searches and scientific activity greatly depends on one's ability to work with modern systems of computer mathematics. Moreover, the process of computer mathematics systems teaching creates new opportunities for student-teacher and student-student correlations. Also, this process enables each student to maximise their intellectual potential.

Nowadays, computer research and experiments are widely used in the process of teaching mathematics at school and university. However, we should underline that a number of drawbacks have been highlighted in studies focusing on the application of interactive mathematical fields in the teaching process. One of the major drawbacks is that the so-called "experimental-theoretical gap" occurs in students' minds. This results in a decrease in students' motivation to find a deductive solution and in a lack of interest in a task-based approach. It maintains the idea that a careful and thoughtful pedagogical analysis and approach should be introduced at school as well as at university when it comes to computer research and experimentation. How should we use technologies in our classes? But simultaneously, another question arises: How should technologies improve what we intend to do in our classes? Teaching is, of course, a priority. And technologies are not the main aim in and of themselves. Ultimately, technology is a useful tool for students who want to advance their educational experience. Besides this, however, technology is of great assistance in the process of education.

The computer is a definite intermediary between the practical and theoretical levels of mathematical understanding and acceptance. It is necessary to bear in mind that the logic of the presentation 
of a systematic course does not refer very much to the process of knowledge acquisition or the role of geometric imagination and intuition within this process. A teacher needs to set research tasks in the way they enable their students to rely on their cognitive skills, not on the computer. The usage of applied programs during students' studies should contribute to their intellectual development but not replace it.

The second trend shows us that geometry permeates almost all spheres of human activity. What is more, geometry is inextricably linked with our ideas of beauty and harmony, rigorous proof, and impeccable logical structure. And to top it all, the richness of human vision significantly increases our opportunities to analyse it. Our vision allows us to detect complex relationships that are not obvious without a visual image of the studied objects. In all likelihood, these factors stimulate us to draw a picture (scheme, diagram or plan) when we aim to solve a difficult problem. In short, we either tend to find a successful visualisation or build a geometric model, i.e. we undertake a geometric task.

Geometric ideas and concepts build a solid foundation of different fields of modern mathematics. The geometric language is the basic and common language of mathematics representatives as well as representatives of other scientific schools. Shaped at school, conceptual and intuitive notions of space serve as the primary basis for subsequent productive generalisations in various fields of scientific knowledge - from generalised and phase spaces in physics to semantic, mental and other spaces in psychology.

Nowadays, geometry plays a unique and exceptional role in school education. Children get to know rigorous geometric proofs in geometry lessons. They learn to think logically and make conclusions based on premises.

At the same time, school geometry demonstrates visual mathematics, which is mainly based on a detailed study of the qualitative properties of geometric objects rather than on formulas. Such a combination of rigour and clarity establishes the basis of a natural scientific picture of the world. Thus, geometry is an essential part of scientific study.

A geometric view of the world pervades all modern mathematics. First of all, the major part of mathematics fields uses geometric language and applies geometric methods. Very often, the penetration 
of geometric ideas into other fields of mathematics leads to the creation of new theories and the formulation of new problems not only in mathematics but also in theoretical physics. Undoubtedly, geometry plays an exceptional role in modern education. Geometry familiarises students with a variety of spatial forms, provides a method of scientific knowledge, and promotes the development of logical thinking. The educational, developing and applied values of geometry are not fading but, on the contrary, are increasing. Classical geometric ideas and concepts form the basis of various fields of modern mathematics, as geometric language and methods are used in the majority of them. Moreover, the geometrisation of many mathematical objects can be noticed and stated now.

\section{The study}

The combination of these two trends is possible based on the general scientific principle of complementarity formulated by N. Bohr. This principle states that opposites do not contradict but rather complement each other.

The principle of complementarity is designed to take into account the properties of an object that are opposite yet complementing each other in a single system. The most important point is to understand the existence of a single system. The principle of complementarity implies that there is a single interpretation of the object under study, that is, there is a single truth, but researchers are forced to move to it from different sides. Identifying two significantly different but interrelated levels in the process of learning geometry (empirical and theoretical), we aim to consider the problem of the correlation of approaches in teaching geometry in higher education. The idea of complementarity appears in the context of solving this problem.

The principle of complementarity in teaching allows us:

1. to solve the didactic problem of developing new methods of teaching geometry based on the use of experiments, the figurative type of information processing, and the traditional approach (without a computer) to consider the problem, research, and experimental methods in unity,

2. to add specifically human elements to the algorithmic "thinking" of modern computers (the computer is considered as a research tool), and 
3. to maintain the balance of fundamental training (knowledge of the axiomatic method, logical methods for proving theorems, etc.) with modern requirements for the graduate.

The principle of complementarity will thus allow the teacher to be qualified in interdisciplinary mathematics.

The world is currently undergoing great changes which require a corresponding emphasis on certain issues and topics. Certainly, these issues and topics can best be revealed in the process of teaching both traditional and new subjects, as well as while teaching subject sections and different themes.

Most of the problems we can find in reality are related to more than one area of disciplinary knowledge. This means that they can be considered as interdisciplinary problems. However, when these problems are approached in school, the approach tends to focus on the knowledge of one specific subject. In particular, and as the review by Williams et al. (2016) shows, interdisciplinarity in mathematics education is a relatively under-developed research subfield.

Children's perception of the world as a list of unrelated subjects is one of the urgent problems of modern school education. Very often, schoolchildren do not understand how to apply the acquired knowledge outside the lesson. It is obvious that, in the process of teaching traditional subjects, the contents of these subjects are isolated from each other. Today, there is often very little communication between disciplines. As a result, an incomplete formation of a holistic picture of the world is created in the children's minds. The idea of interdisciplinarity is to combine multiple academic disciplines into one activity. The literature offers a variety of ways to understand interdisciplinarity (e.g. Rocha, 2019; Ferri \& Mousoulides, 2017). We use a definition formulated by Roth, who stated the following: "Interdisciplinarity denotes the fact, quality, or condition that pertains to two or more academic fields or branches of learning. Interdisciplinary projects tend to cross the traditional boundaries between academic disciplines" (2014, p. 317).

The implementation of an interdisciplinary approach in teaching is aimed at creating an educational environment in which students perceive the world as whole and unique, but not as a list of individual subjects studied at school. 
To overcome this trend, the idea of interdisciplinary education has long been brainstormed and shared in the pedagogical community. Undoubtedly, interdisciplinary education focuses on the formation of an integral picture of the world in the child's mind. However, the practical implementation of this concept faces significant obstacles. First and foremost, the predominance of the subject-oriented approach at modern schools hampers this process.

A teacher needs to be aware of the space of interdisciplinary ideas to shift the vector of school education from a subject-oriented to an interdisciplinary one. Interdisciplinarity at school can and should be initialised and taught by a teacher. This means that an interdisciplinary approach should be applied in the framework of prospective teacher training.

\section{Results}

Undergraduate (bachelor level) and postgraduate (Master's level) mathematics teacher training in Russia is provided at universities and pedagogical institutes. At the level of bachelor studies at Saratov State University, graduates are expected to acquire the following theoretical knowledge: an awareness of the psychological interpretation of human development, upbringing, and education; the principles of creating and designing educational and didactic environments in secondary education; a good awareness of the organisational characteristics of the school system as well as the institutional principles and rules of the school; and the content of mathematics and the methods of teaching mathematics. Graduates are also expected to acquire the theoretical knowledge content of the one domain specialisation that they teach.

An experimental research approach to the study of geometry at the university is implemented by us in the classes on geometry ( $1^{\text {st }}$ and $3^{\text {rd }}$ years) as well as on the subject "Fundamentals of research activities in the field of mathematical education" (from $2^{\text {nd }}$ to $4^{\text {th }}$ years). The use of computer research and experiments when teaching mathematics in the framework of higher education allows us to improve the content of academic courses, increase the number of tasks and exercises for self-study, develop practical skills for conducting mathematical reasoning, and simulate and illustrate the concepts and objects being studied. These aspects will give students an opportunity to explore certain topics thoroughly, motivate them, and increase 
interest in the discipline as a whole. Besides, the use of computer tools can positively affect not only teaching methods but also the content of academic disciplines.

On the one hand, in practical classes on analytical geometry and differential geometry, in the framework of extracurricular work, students solve educational and research tasks using a computer experiment. The main software used is GeoGebra and Wolfram Mathematica. On the other hand, students of the subject "Fundamentals of research activities in the field of mathematics education", in particular, learn in the classroom to use an experimental approach in school geometry.

The methodology for the organisation of experimental research activities of future teachers of geometry is as follows:

1. the selection of content, taking into account the following requirements: the possibility of developing a cognitive interest in the study of geometry; the possibility of developing logical and imaginative thinking; and the possibility of applying the research aspect in the process of solving geometric problems;

2. the choice of forms of organisation of the educational activities of future bachelor studies students, based on the educationalmethodical approach to solving geometric problems, independent work in the framework of academic disciplines, and performing term papers and final qualification works;

3. the selection of productive (problematic, search, research) teaching methods (Bryman, 2004).

We adhere to the tiered model of research training developed by Banchi and Bell (2008):

Level I: Confirmation Inquiry. This level is the most familiar and the easiest to do. At this level, you will develop both the questions and a procedure that will guide students through an activity with known results.

Level II: Structured Inquiry. This level is similar to Level I, but also involves developing a foundation for inquiry and critical thinking skills. You will provide an initial question and an outlined procedure for students to follow. It is important, however, that the results are unknown. 
Level III: Guided Inquiry. This level allows students to take more ownership of the experiment and findings. They are responsible for designing the procedure and following it to answer the question that you provided. Learners build upon the skills gained from earlier levels, as well as incorporate more problem solving and critical thinking skills. Because learners now have more freedom in developing the procedure and finding useful content, it is important for you to provide guidance and feedback where necessary.

Level IV: Open Inquiry. At the highest level of inquiry-based learning, within broad parameters, learners establish ownership of the experiment and findings. They are allowed to choose a topic or idea that is of interest and begin to formulate their own research question(s) and design a procedure to conduct the study. Once the study is complete, you may have them prepare a report or presentation detailing the findings and results.

It is reasonable to develop new content for studies through a system of tasks. In other words, a task-based approach should also be taken into consideration.

It is a well-known fact that problem solving is a crucial aspect of educational activity. The task-based approach is an educational activity that requires the involvement of all members (objects) of the educational process. This approach also includes the application of a system of diverse tasks and their solutions. This means not only certain task systems but also systems that ensure the success of their solution are defined within the task-based approach. The Polish mathematician Maciej Klakla has paid much attention to and thoroughly examined multi-stage mathematical tasks (Klakla, 2003). He regards them as the main source for the formation of the creative mathematical activity of Polish students in schools specialised in the study of mathematics.

Let us give an example of problems in analytic geometry, the solution of which we can find using the dynamic geometry of GeoGebra. The task is to experimentally verify and prove the following statements: (1) tangents to the hyperbola form equal triangles with asymptotes; and (2) the segment of any tangent hyperbola enclosed between the asymptotes is divided in half at the point of tangency. To conduct a computer experiment on a GeoGebra graphic canvas, in accordance 
with the condition of the problem, we construct a hyperbola, asymptotes, and a tangent at an arbitrary point. Moving the point along the hyperbola, it will be seen that the area of the triangle remains constant. The hypothesis that follows from this is that tangents to a hyperbola form equal triangles with asymptotes. Further, students need to theoretically justify the assumptions obtained.

These tasks belong to Level I, i.e. students verify the validity of known research results. Based on the solved problem, the teacher, in an interview with students, identifies the composition of the goal-setting method: (1) put forward a hypothesis, (2) draw up a hypothesis testing plan, and (3) divide the task into subtasks (stages of the plan's implementation). On the Euclidean plane (in space), many other similar problems can also be given. Using application programs, students can independently discover patterns between geometric objects.

The tasks of Level II (Structured Inquiry) make it possible to evaluate and diagnose the knowledge of factual material (basic concepts, algorithms, facts) and the ability to correctly use special terms and concepts and to recognise objects of study within a specific section of the discipline. For example, (1) construct bending: a simple piece of a cylinder on a simple piece of a plane; a simple piece of a plane onto a simple piece of a cone; a catenoid to a helicoid; (2) on a hyperbolic paraboloid, visualise rectilinear generators passing through a dynamically given point on the surface, and set the position of the point with a twodimensional slider to study the mutual position of the generators of one family.

Solving differential geometry problems (curves and surfaces in Euclidean space) using application programmes is more consistent with Level III (Structured Inquiry). Tasks of a creative level allow us to evaluate and diagnose skills, integrate the knowledge of various fields, and argue our point of view. Let us examine the example of the problem of constructing geodesic surfaces. It is recommended to study the behaviour of geodesics on a torus, sphere, and cylinder embedded in a Euclidean three-dimensional space as computer research.

The interdisciplinary component of students' research work helps to improve the quality of their mathematical training. Students form ideas about the types of interdisciplinary connections between mathematics (geometry) and other disciplines, the ability to apply 
them in solving problems, and increase their motivation and enhance their educational and cognitive activities. In studies on convergent, information-cognitive technologies, it is noted that the basis of the new system of organisation of science and education is interdisciplinarity (Bainbridge \& Roco, 2005).

What should be done to make knowledge more interdisciplinary? It is appropriate initially to consider ways of identifying links between fields of science, as knowledge goes beyond the framework of one discipline. A powerful way to illustrate ideas and instantly make them relevant to students is to emphasise the interdisciplinary application of ideas, meta-ideas, methods, and tools.

In 2019, a campaign for teachers was held in Russia. The " 5 by 5 " campaign represents training for teachers in the format of the Russian National Examination (RNE) and includes preparation for five school subjects. This campaign is held in support of graduates who are going to take the RNE. Moreover, the campaign helps to identify and support teachers with great erudition, high intelligence, and a broad outlook. It gives much prominence to those who clearly understand interdisciplinary connections and are good at their subjects as well as at various subjects from other fields of science. The teacher has a completely different view of his subject among other subjects and even gets a new understanding and perception of the problems discussed in the school course.

A question therefore arises: how ready are students (prospective mathematics teachers) to use an interdisciplinary approach in teaching schoolchildren?

We conducted an empirical study with students in the $2^{\text {nd }}$ to $4^{\text {th }}$ years of their study. In the "Fundamentals of research activities in the field of mathematical education" classes, students studied, became acquainted with, and solved interdisciplinary tasks from the fields of mathematics (geometry), physics and computer science at the school level.

These are some examples of their tasks:

1. The coefficients of the equation of the line $a x+b y+c=0$ and the coordinates of point $A\left(x_{a^{\prime}} y_{a}\right)$ are given. Find point $B$, which is a reflection of point $A$ relative to a given line.

Input: the coefficients of the equation of the straight line $a, b$, $c$ are entered from the keyboard, then the coordinates of point $A$. 
The initial data are integers and modulo not exceeding 1000. Output: print the coordinates of point B up to the fifth decimal place.

2. The depth of a pond is two metres. Determine the apparent depth of the pond if its bottom is examined by bending over the water and looking vertically down. The refractive index of water is 4/3. The angles are considered small.

3. A plane flies in calm weather with a speed $v$ horizontally at a height $h$. The pilot must dump his cargo at a point in front of the aircraft. At what angle to the horizon should he see the target at the moment of dropping the load? Do not consider air resistance.

Such tasks can be of great help to students by providing them with a clear understanding of the fact that many problems can be solved if we consider them from the point of view of different subjects. Also, the creation of a project makes it possible for schoolchildren to realise that the knowledge and skills acquired and formed in the course (educational process) give a better understanding of the problem. Besides, the project forms a new understanding (idea/vision) that cannot be achieved without mastering the content of several subjects.

The processing of our study was carried out using the Wilcoxon test. The findings in this study revealed that second-year students solved interdisciplinary tasks in all three domains with great interest. Perhaps this is because students still remembered the school curriculum well. The third-year students solved all problems with approximately equal interest. Fourth-year students showed better results and showed greater interest in only two subjects: mathematics and computer science. A student (prospective teacher) has a completely different view of his domain among other domains and even gains a new understanding and perception of the problems discussed in the school course. Our study will continue, but the preliminary conclusions are as follows: the students were able to see the connection of mathematics with other subjects, and they expressed an interest in and willingness to develop such new disciplines as artificial intelligence and data analysis. 


\section{Discussion}

Geometric activity (of various categories of students), as a rule, has a complex structure. On the one hand, it is the formation and development of spatial representations that reflect the perception of a real physical space and the design and transformation of the corresponding mathematical model-geometric space and its ideal objects in figurative, symbolic forms. On the other hand, it is geometric thinking, starting with the simplest methods of classification, the analysis of geometric shapes, intuitive and logical means of proving their properties, and ending with formal logical reasoning in the framework of the axiomatic method. The emergence of computers in everyday life has opened up opportunities for the technological support of learning methods that were previously technologically inefficient. The development of computer tools allows you to significantly change all the components of the methodological system of teaching geometry. It is necessary, however, to continue searching for new forms of human-computer interactions aimed at developing students and their deep understanding of mathematics.

\section{References}

$\rightarrow$ Arnold, V.I. (1997). Mathematics and mathematical education in the modern world, Mathematical Education, 2, 109-112.

$\rightarrow$ Bainbridge, M.S. and Roco, M.C. (2005). Managing Nano-Bio-Info-Cogno Innovations: converging technologies in society. Dordrecht: Springer.

$\rightarrow$ Banchi, H. and Bell, R. (2008). The many levels of inquiry, Science and Children, 46(2), 26-29.

$\rightarrow$ Bryman, A. (2004). Social research methods. Oxford: Oxford University Press.

$\rightarrow$ Chartouny, M., Iman, O. and Raad, A.-N. (2019). A model of the instrumentation process in dynamic geometry. In: U.T. Jankvist, M. van den Heuvel-Panhuizen, M. Veldhuis (eds.), Proceedings of the Eleventh Congress of the European Society for Research in Mathematics Education (pp. 769-776). Utrecht: Freudenthal Group \& Freudenthal Institute, Utrecht University and ERME.

$\rightarrow$ Ferri, R. and Mousoulides, N. (2017). Mathematical modelling as a prototype for interdisciplinary mathematics education? Theoretical reflections, CERME 10, https://hal.archives-ouvertes.fr/hal-01933490

$\rightarrow$ Klyaklya, M. (2003). Formation of the creative mathematical activity of students in classes with in-depth study of mathematics in Polish schools. Moscow: MGPU. 
$\rightarrow$ Leontiev, A. (2009). The Development of Mind, www.marxists.org/admin/books/ activity-theory/leontyev/development-mind.pdf

$\rightarrow$ Papert, S. (1980). Mindstorms: Children, Computers, and Powerful Ideas. New York: Basic Books.

$\rightarrow$ Poincaré, H. (1921). The Foundations of Science. New York: Science Press.

$\rightarrow$ Pozdniakov, S. (2019). Computers in the productive learning of mathematics. In: A. Shvarts (ed.), Proceedings of the PME and Yandex Russian conference: Technology and Psychology for Mathematics Education (pp. 77-90). Moscow: HSE Publishing House.

$\rightarrow$ Rocha, H. (2019). Interdisciplinary tasks: Pre-service teachers' choices and approaches. In: L. Leite, E. Oldham, L. Carvalho, A.-S. Afonso, F. Viseu, L. Dourado, H.-M. Martinho (eds.), Proceedings of the ATEE Winter Conference-Science and mathematics education in the $21^{\text {st }}$ century (pp. 82-93). Brussels: ATEE-CIEd.

$\rightarrow$ Roth, W.-M. (2014). Interdisciplinary approaches in mathematics education. In: S. Lerman (ed.), Encyclopedia of mathematics education (pp. 317-320). Berlin, Heidelberg: Springer.

$\rightarrow$ Sinclair, N., Bartolini Bussi M.G., Villiers, M. de, Jones, K., Kortenkamp, U., Leung A. and Owens, K. (2017). Geometry education, including the use of new technologies: a survey of recent research. In: G. Kaiser (ed.), Proceedings of the $13^{\text {th }}$ International Congress on Mathematical Education, ICME-13 Monographs (pp. 277-287). Cham: Springer.

$\rightarrow$ Thomas, M.O.J. and Palmer, J.M. (2014). Teaching with digital technology: obstacles and opportunities. In: A. Clark-Wilson, O. Robutti, N. Sinclair (eds.), The mathematics teacher in the digital era an international perspective on technology focused professional development. An International Perspective on Technology Focused Professional Development (pp. 71-89). Dordrecht: Springer.

$\rightarrow$ Vygotsky, L.S. and Luria A.R. (1994 [1934]). Tool and symbol in child development. In: R. van der Veer, J. Valsiner, The Vygotsky Reader. Hoboken: Wiley-Blackwell.

$\rightarrow$ Williams, J., Roth, W.-M., Swanson, D., Doig B., Groves, S., Omuvwie, M., Borromeo Ferri R. and Mousoulides, N. (2016). Interdisciplinary mathematics education: a state of the art (ICME-13 topical surveys). Dordrecht: Springer. 